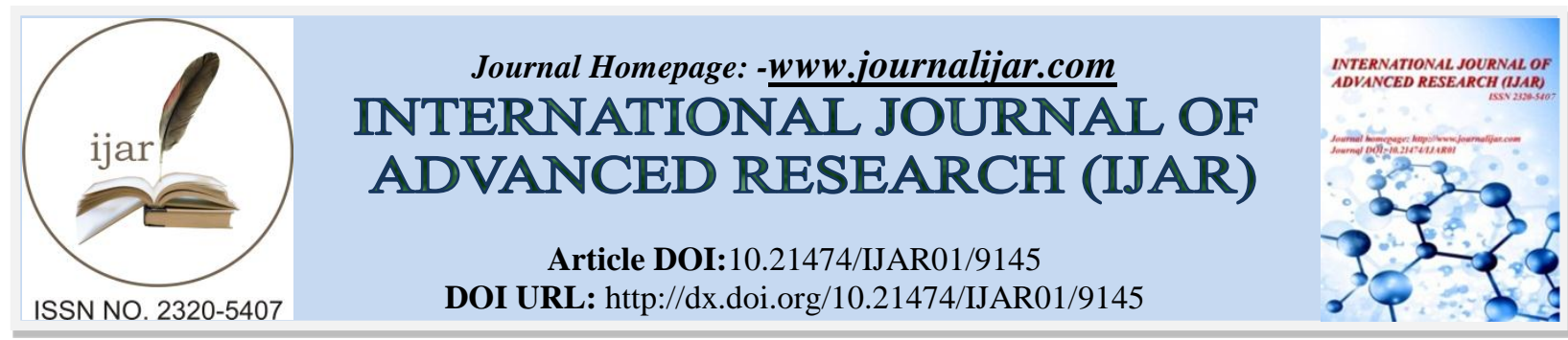

RESEARCH ARTICLE

\title{
THE NEEDS OF INFORMATION TECHNOLOGY BASED ACCOUNTING RECORD IN INDONESIA SMALL AND MEDIUM ENTERPRISES (SME'S).
}

\author{
Agnes Utari Widyaningdyah, Tineke Wehartaty And Hendra Wijaya. \\ Widya Mandala Catholic University of Surabaya.
}

\section{Manuscript Info}

\section{Manuscript History}

Received: 24 March 2019

Final Accepted: 26 April 2019

Published: May 2019

Key words:-

SMEs, Selection of accounting app, Operational, Completeness,

Personalization, Support, Strategic.

\begin{abstract}
Background: This study investigates factors to be considered by small and medium enterprises (SME) owners in choosing accounting applications (apps) that can assist their business operations. This research involves SMEs in East Java province of Indonesia. This is due to the consideration that SMEs in East Java contribute $57.5 \%$ of gross regional domestic product.

Research method: This research is an exploratory study using the principal component analysis (PCA).

Results: The study found that there were five factors that were considered by SME owners in selecting accounting app. These factors were operational, complete, personalized, support, and strategic. Operational factors were related to the support of accounting app for the sustainability of the company's operations. Completeness factors were related to the features available in the accounting app - it was complete so that it could support current and future business operations. Personalization factors were related to the flexibility of accounting app in modifying the generate output according to the user needs. Support factors were related to facilities and infrastructure that had to be possessed by the company before using the accounting app, so that the app could run perfectly. The last factor - strategic - was associated with the ability of accounting app in meeting the needs of the company in the future, including the ability of accounting app integrated with other devices.
\end{abstract}

Copy Right, IJAR, 2019,. All rights reserved.

\section{Introduction:-}

Various studies have revealed a change in the role of accounting functions resulting from the emergence of information technology (Sarosa, 2008; Smirat, 2013; Ammanamah, Morrison, \& Assiedu, 2016). The implementation of tools and information technology has substantially changed the responsibilities of corporate reporting by increasing access to timely, quality, and comprehensive information. Regardless of size, type and structure, companies around the world have demonstrated the role of information technology as an enabler in the industrial and trade fields. Information technology support is also accompanied by excellence in professional accounting practices. Various benefits can be obtained from the use of information technology: improving information processing capabilities and operational efficiency, reducing cost, and ultimately accelerating the achievement of competitive advantage (Moghaddam, Baygi, Rahmani, \& Vahediyan, 2012).

Corresponding Author:-Agnes Utari Widyaningdyah.

Address:-Widya Mandala Catholic University of Surabaya. 
The use of information technology has increased the efficiency of financial transaction processes, one of which is the adoption of accounting app - bringing about the increase of the expected quality and quantity of accounting data used in management decision making (Fisher \& Fisher, 2001). The use of accounting app in managing accounting information has evolved over the years and is now an integral part of the operations of an organization. Acquisition of app to support financial transactions is a very important stage, and its success is highly dependent on business strategy alignment (Widyaningdyah, 2014). According to Hall (2011), the high cost of app development and the low cost of commercial app, which is accompanied by changes in accounting data processing is the reason why many companies prefer buying commercial app to developing the app themselves.

The need to align information technology and corporate strategy is a key for success for the sake of creating competitive advantage. However, it should be realized that app development - both developing the app and buying commercial app packages - is very expensive. The biggest challenge in acquiring app is actually not in its installation, training, data conversion, or backup. The real challenge goes to operational and strategic consequences that are caused by the wrong choice of app. Financial losses, hampered company operations, and the loss of strategic opportunities can be experienced by companies that choose the wrong app (Abu-Musa, 2005).

The decision to obtain and replace accounting app used in a company's accounting information system is something very essential. A company is expected to be able to identify accounting app according to the company needs. According to Simkin (1992) the decision to select accounting app is a strategic decision. Consideration of the complexity of operations and processing of financial transactions, the frequency of reporting, the need for special information, and the integration of interfaces are required in choosing accounting app. The plentiful commercial accounting app makes it increasingly difficult for one to decide which app fits the company needs. Various studies have discussed the importance of accounting app (Spathis \& Constantinides, 2004; Tijani \& Mohammed, 2013; Al Amin, Yeoh, \& Waren, 2015; Fitriati \& Mulyani, 2015; Lutfi, Idris, Muhammad, 2016; Amanamah et al., 2016) and the use of information and communication technology-based accounting information systems which have an effect on performance (Ismail \& Zin, 2009; Budiarto, 2014; Al-dmour; Al-Fawaz, Al-dmour, \& Allozi, 2017). However, what factors are taken into consideration in the selection of accounting app have not been discussed in depth. The framework proposed by Abu-Musa (2005) and Jhadav and Sonar (2011) has not been applied in empirical research to find practical evidence related to the factors considered by companies in choosing accounting app. Based on these reasons, this study seeks to further examine the factors that are taken into consideration in identifying the needs of accounting app.

The importance of accounting information systems is not only limited to large-scale companies. Small-scale companies also need accounting information that determines the company's operational sustainability. Companies in the category of small and medium enterprises (SMEs) in various countries play a very important role in the economy. As is the case in Indonesia, based on data from the 2013 Central Bureau of Statistics, the number of SMEs is 57.90 million units with a total contribution to gross domestic product (GDP) of Rp 1,237 billion indicating the importance of small businesses for the Indonesian economy. Likewise, the number of small businesses in East Java reached almost seven million units, with contributions to gross regional domestic product (GRDP) reaching 54.98\%, making small businesses in East Java play a very important role in the East Java regional economy.

The importance of the role of small businesses is expected to be followed by financial management capabilities as reflected by good accounting records. Government Regulation of Republic of Indonesia Number 17 of 2013 with regard to the implementation of Law Number 20 of 2008 concerning SMEs requires small businesses to make good accounting records. In addition to getting access to funding from banks, good accounting records are needed by small businesses to be able to control production costs, find out financial positions, and assist managers to make good decision. Therefore, small businesses in Indonesia are in real need of tools that are able to meet the needs of recording good financial transactions. Lack of adequate knowledge of accounting and information technology, as well as limited capital are the main obstacles faced by small Indonesia businesses in determining the selection of accounting information systems.

This study seeks to explore what factors are considered by SMEs in selecting accounting app for recording financial transactions. This research is a preliminary study of a series of studies aiming to determine the alignment between what accounting app is used and what is needed and how it fits with the company's objectives as stated in its business strategy. 
The limited research that explores factors to be considered in selecting accounting app, especially in SMEs in Indonesia is the motivation that drives this research. In addition, SMEs in Indonesia practically requires a framework that can be used as a guideline in selecting accounting app that suit their needs. Based on this, the research question of this study is "What factors are considered by SMEs in Indonesia in selecting accounting app to be implemented?" This research is in the long run expected to contribute to develop the knowledge regarding the factors considered in selecting accounting app, and for SME owner to encouraging the use of information technology based accounting record in order to make their business more efficient.

\section{Literature review:- \\ Information Processing Theory}

Information processing theory was put forward by Galbraith (1973 in Ismail \& King, 2005). This theory states that the capacity of information processors must be in accordance with the needs of information processing - revealing that the availability of information processing facilities must be able to meet the company's information processing needs. This theory assumes that an organization (in this case a company) is a complex system that faces the main problems (related to its environment) in the acquisition and utilization of information. The higher the environmental uncertainty, the more information needed to be processed in order to achieve a certain level of performance. Companies must respond to these information needs by enhancing the capacity of information processors.

Although this theory first appears in large industries, several studies have succeeded in adopting it for SMEs (El Luodi, 1998, Ismail \& King, 2005, Khazanchi, 2005, and Venkatesh, Thong, \& Xu, 2012). Thus the theory of information processing can be applied to both small, medium and large companies. Moreover, this theory is also reinforced by the literature written by Van de Ven and Drazin (1985) who state that the product of companies is a consequence of the suitability of two or more factors. If it is associated with information processing, the company's products are the result of the compatibility capacity or facilities with information processing needs.

In addition to information processing theory, the concepts from Markus and Tanis (1997) - the concept of value creating effects of information technology - are used in this study. This concept highlights that there are three things to know whether information technology has added value or not. First, information technology development and selection is an opportunity, which involves the complexity of behavior and changes in customer demand, technological obsolescence and dynamism of the external environment. Second, information technology initiation process is a stage that involves the selection and development of information technology, implementation, and post implementation that requires users' feedback. Third, factors that greatly influence the selection and development of information technology are the company's external factors which often weaken the focus of information technology selection and development.

\section{Alignment Theory}

The alignment theory used as the basis of this research is the alignment between the development of information technology with the needs and business strategies of companies (Ismail \& King, 2014; Disnayake, 2012). This theory is the basis for the success in doing business since this theory synergizes the design and development of information technology with business strategies that have been set by companies.

The challenge faced in the alignment process is the emergence of inconsistencies between the desire of companies and the services provided by information technology. The inconsistency between business strategy and information technology is associated with the misalignment of companies' needs for accounting information with information technology capabilities in processing that information (Ismail \& King, 2014). The inability of information technology in processing information is caused by the differences in the goals and objectives of each department (King \& Teo, 1996).

Alignment should also occur in the process of selecting an accounting app that will be used as an enabler in the business processes. The accounting app that will be used should be in accordance with the needs of companies and it should support companies to achieve the predetermined business strategy. Consequently, the use of accounting apps with information technology and strategies and company needs can be in harmony with each other.

\section{Determination in Accounting Application Selection}

The main purpose of selecting accounting app is to adjust between product features (in this case, accounting app) to the needs of users. Collins (1999) states that the feature that must be possessed by accounting app is its ability to be customized to suit the company needs. The kinds of customizations include: being able to produce the various 
financial reports needed and being able to make various transaction forms and documents, interactive screen displays, multi-currency usage, and flexible database usage.

In addition to ability in customization, supplier (vendor) reliability is a very critical consideration in choosing accounting app. The accounting app supplier will be the company's business partner for a very long time. Therefore, it is necessary to consider the ability of suppliers to support the company business needs in the future, including the use of information technology that accompanies the app.

Easy-to-use accounting app that is compatible with other devices is also an important consideration. The reason is that in its development, information technology requires networks especially the internet, so accounting app that is compatible with the network is very crucial nowadays. The use of web and e-commerce should be supported by selected accounting app (Muhrtala \& Ogudenji, 2014).

\section{Research method:- \\ Population and Sample}

The population and sampling frame of this study were all small and medium enterprises listed in the Profile of East Java Regency, Leading SMEs according to the East Java Province Cooperation, and Micro, Small and Medium Enterprises Office in 2017. The term SMEs used in this study refers to the Ministry Cooperation Countries and Micro, Small and Medium Enterprises, namely businesses whose sales (turnover) are below or equal to 50 billion Rupiah per year. Purposive sampling technique was employed using the following criteria:

1. Having a clear position or address.

2. Having a contact person who can be called.

3. Having a business process that is run continuously rather than based on certain events.

4. Carrying out simple accounting records regularly.

5. Wanting to participate in a research survey

The unit of analysis of this study was the companies included in the SME category with respondents who owned SMEs. The SME owners were chosen as the respondents for they possessed the responsibility of selecting SME resources, including the selection of accounting app.

\section{Types and Data Sources}

The type of data used in this study was primary data obtained through surveys by distributing a set of questionnaires to respondents. The data source was the score of each variable indicator obtained from the questionnaire.

\section{Procedure of Data Collection}

Each micro, small and medium business owner who became a respondent received the questionnaire. The owner became the respondent in this study with the consideration that small and medium business owners were considered to be those who were most aware of the need for ICT-based AIS and AIS development in the future. The questionnaire was collected through google form or printout so that the results could be received and processed immediately. In addition, many SME owners currently used online media, both web and social media so onlinebased data collection was expected to reach wider SME owners.

\section{Operational Definitions and Variable Measurements}

This research was exploratory on the characteristics of ICT-based AIS required by SMEs. The statements in the questionnaire were therefore presented as a whole without looking at grouping statements into certain constructs. The characteristics of ICT-based AIS referred to in this study were the selection of accounting app used by SMEs. Grouping were done using the principal components analysis after the data from the questionnaire were collected. The items of the statement submitted referred to the study of Abu-Musa (2005) and Muhrtala and Ogundeji (2014) (attached).

Survey questions were divided into two parts. The first part consisted of questions related to the demographics of the respondents, while the second part consisted of the issue related to the main consideration of respondents in choosing ICT for AIS that was implemented in the company. Instruments or statement items were measured using a Likert scale which ranged from 1 indicating the answer of "not priority" to 5 "essential". 


\section{Data Analysis Techniques}

Before the questionnaire was distributed to the respondents, a pilot study was conducted to find out whether there were statements that were not understood by the respondents; improvements in terms of language and content would be needed if necessary. The pilot study involved several SME owners in Surabaya and experts and academics involved in the field of accounting information systems. Respondents who had participated in the pilot study were not included as actual research respondents. The next step was to revise the questionnaire until the questionnaire was ready to be disseminated through online media.

The data that had been obtained were tested in advance for the validity and reliability of the instruments to avoid bias. The validity test employed in this study referred to the one proposed by Bartlett and Kaiser-Meyer-Olkin (KMO) (Ghozali, 2014:55). If the value of Bartlett and Kaiser-Meyer-Olkin (KMO) was greater than 0.05, the indicator was said to be valid for testing factor analysis. The reliability test for the instrument was done by Cronbach Alpha testing (the factors are said to be reliable if it is greater than 0.7 (Ghozali, 2014:48)).

After the indicator was said to be valid and reliable, the next step was to do orthogonal rotation testing. Orthogonal rotation was done to group indicators into certain groups of factors. The rotation used was to rotate the axis $90^{\circ}$ (Ghozali, 2014:378). After the rotation was done, the next step was to do principal components analysis (PCA) by grouping instrument indicators into the main factors called factorial analysis. The focus would be on the factor loading of each indicator - which must be greater than 0.05 (Simamora, 2005). Besides, the focus was also on the relationship between indicators to create strong factors in forming the construct. This was done by paying attention to questions or statements that were interrelated in a factor.

\section{Results and discussions:- Respondents}

As previously mentioned, before the final questionnaire was distributed to the respondents, it was tested. This was done because the research instrument was translated from English into Indonesian. The pilot test was in the form of pre-testing to get input. It was conducted by involving five people consisting of academics and practitioners. Minor revisions were made based on the input from the respondents. It was expected that instruments could be understood more easily.

The respondents of this study were the owners or managers of companies belonging to SMEs registered in the Profile of East Java Regency or City as leading SMEs according to the East Java Provincial Cooperation and SME Office in 2017. About 500 respondents were sent questionnaires during the period of 2 August 2018 till 10 December 2018. There were 60 questionnaires returned. Of the 60 questionnaires, only 58 could be further processed because two questionnaires were not filled in completely. The general description of respondents can be seen in Table 1.

\section{Respondent Demographics}

In this section, the demographics of the research respondents will be described based on the business domicile, sales per year, industry type, age, and information and communication (ICT) use, as can be seen on Table 2.

Table 1:-Descriptive Statistics: Questionnaires

\begin{tabular}{|l|r|}
\hline \multicolumn{1}{|c|}{ Note } & \multicolumn{1}{c|}{ Total } \\
\hline Sent & 500 \\
\hline Not returned & 440 \\
\hline Returned & 60 \\
\hline Returned but not completed thoroughly & $(2)$ \\
\hline Analysed & 58 \\
\hline Response rate & $12 \%$ \\
\hline Usable response rate & $11.6 \%$ \\
\hline
\end{tabular}

Table 2:-Respondent Demographics

\begin{tabular}{|l|c|c|}
\hline \multicolumn{1}{|c|}{ Criteria } & Unit & Percentage \\
\hline Business location & & \\
\hline Surabaya & 34 & $59 \%$ \\
\hline
\end{tabular}




\begin{tabular}{|c|c|c|}
\hline Sidoarjo & 16 & $27 \%$ \\
\hline Outside Surabaya and Sidoarjo & 8 & $14 \%$ \\
\hline \multicolumn{3}{|l|}{ Sales per year } \\
\hline Micro Enterprises (< Rp 300.000.000,00/year) & 26 & $45 \%$ \\
\hline $\begin{array}{l}\text { Small Enterprises (> Rp 300.000.000,00 and }<\mathrm{Rp} \\
2.500 .000 .000,00 / \text { year) }\end{array}$ & 24 & $41 \%$ \\
\hline Medium Enterprises (< Rp 300.000.000,00/year) & 8 & $14 \%$ \\
\hline \multicolumn{3}{|l|}{ Industry type } \\
\hline Manufacture & 25 & $40 \%$ \\
\hline Trade & 29 & $50 \%$ \\
\hline Service Company & 4 & $10 \%$ \\
\hline \multicolumn{3}{|l|}{ Company age } \\
\hline$\leq 5$ years & 10 & $17 \%$ \\
\hline$>5-20$ years & 33 & $57 \%$ \\
\hline$>20$ years & 15 & $26 \%$ \\
\hline \multicolumn{3}{|l|}{ Using ICT } \\
\hline Yes & 35 & $60 \%$ \\
\hline No & 23 & $40 \%$ \\
\hline
\end{tabular}

From Table 2 it can be seen that $59 \%$ of respondents had a business location in Surabaya, with $86 \%$ were owners of micro and small scale businesses. This was in line with the data from the Central Bureau of Statistics in 2018. The number of micro and small businesses had increased considerably, reaching about 3-4\% per year. most respondents were engaged in trade, while $40 \%$ were engaged in manufacturing, and the remaining were in the service sector. There were quite a lot respondents in trade because most SMEs in East Java were engaged in buying and selling handicraft products and also some businesses producing their own handicrafts. These data were in accordance with the Central Bureau of Statistics data in 2018 revealing that the number of micro and small industries engaged in manufacturing and trade occupied a portion of $90.96 \%$ of the total types of micro and small industries in Indonesia. From Table 2 we can also see that the SMEs had been operating for more than five years. Therefore, the respondent's business had been running continuously and had sufficient experience in adapting to the surrounding business environment. Micro, small and medium enterprises are expected to further develop their business by utilizing information technology (Widyaningdyah, 2014). The intended use of information technology in this study led to the use of accounting apps that functioned in recording company transactions and at the same time in preparing the company financial statements. It is indicated that $60 \%$ of respondents had used information technology, especially accounting apps. However, this study did not explore further the types of accounting apps used.

\section{Descriptive Statistics}

This section describes the results of descriptive statistics in the form of minimum, maximum, average, and standard deviations of the characteristics of AIS which consisted of 30 indicators. The results of descriptive statistical analysis of the characteristics of AIS indicators can be seen in Table 3 which revealed that there were five indicators with a minimum value of 2 namely AIS 2, AIS 6, AIS 7 and AIS 8 with the same maximum value of 5 . These results indicated that the respondents considered the indicator to be quite important and a priority. This result was also supported by the average respondent's answers to all indicators used in measuring respondents' perceptions of the factors considered in the selection of accounting app. The average value of respondents' answers tended to reach the value of 4 meaning that the factors and features mentioned in the instrument indicators of this research were considered important and it became the respondents' priority in making choices on accounting app that would be or had been used. 
Some indicators as presented in Table 3 show the standard deviation values that were more than 1 . This means that there was a gap in perception among the respondents one another. Therefore, caution was needed in interpreting the results of this study. However, to test whether there was a bias in the respondent's answers, further testing of the validity and reliability of the indicator was carried out.

Tabel 3:-Descriptive Statistics of AIS Characteristics

\begin{tabular}{|l|c|c|c|c|}
\hline Indicator No. & Minimum & Maximum & Mean & Standard Deviation \\
\hline AIS1 & 1 & 5 & 4,26 & 0,87 \\
\hline AIS2 & 2 & 5 & 4,36 & 0,77 \\
\hline AIS3 & 2 & 5 & 4,24 & 0,89 \\
\hline AIS4 & 1 & 5 & 4,26 & 1,25 \\
\hline AIS5 & 1 & 5 & 3,69 & 0,77 \\
\hline AIS6 & 2 & 5 & 4,41 & 0,91 \\
\hline AIS7 & 2 & 5 & 4,33 & 1,03 \\
\hline AIS8 & 2 & 5 & 4,22 & 0,84 \\
\hline AIS9 & 1 & 5 & 4,41 & 1,05 \\
\hline AIS10 & 1 & 5 & 4,34 & 1,28 \\
\hline AIS11 & 1 & 5 & 3,52 & 1,08 \\
\hline AIS12 & 1 & 5 & 4,24 & 0,94 \\
\hline AIS13 & 1 & 5 & 4,31 & 1,18 \\
\hline AIS14 & 1 & 5 & 4,14 & 1,12 \\
\hline AIS15 & 1 & 5 & 4,02 & 1,19 \\
\hline AIS16 & 1 & 5 & 4,09 & 1,31 \\
\hline AIS17 & 1 & 5 & 3,90 & 1,08 \\
\hline AIS18 & 1 & 5 & 4,24 & 0,96 \\
\hline AIS19 & 1 & 5 & 4,48 & 0,95 \\
\hline AIS20 & 1 & 5 & 4,21 & 1,25 \\
\hline AIS21 & 5 & 3,76 & 0.98 \\
\hline AIS22 & 1 & 5 & 4,12 & 1,09 \\
\hline AIS23 & 1 & 5 & 4,07 & 0,98 \\
\hline AIS24 & 1 & 5 & 4,34 & 1,21 \\
\hline AIS25 & 1 & 5 & 4,03 & 1,24 \\
\hline AIS26 & 1 & 5 & 4,07 & 1,22 \\
\hline AIS27 & 1 & 5 & 3,91 & 0.10 \\
\hline AIS28 & 1 & 5 & 3,267 & 0,96 \\
\hline AIS29 & 1 & 5 & 4,47 & \\
\hline AIS30 & 1 & & & \\
\hline & & 5 & \\
\hline
\end{tabular}

Reliability and Validity

Reliability testing of the indicators used in the instrument was carried out by looking at the Cronbach Alpha value of all 30 AIS characteristics indicators. The following table shows the results of the reliability test for the AIS:

Table 4:-Reliability Test Result

\begin{tabular}{|c|c|c|}
\hline Cronbach Alpha & $\begin{array}{c}\text { Cronbach Alpha } \\
\text { based on Standardized Item }\end{array}$ & N of Item \\
\hline 0,931 & 0,931 & 30 \\
\hline
\end{tabular}

Based on the Table 4, the Cronbach Alpha was 0.931. Thus it can be said that the indicators were reliable - the indicators used as questionnaire instruments had a consistency value for various measurements. In addition to reliability testing, validity testing was also calculated by using the value of Bartlett and KMO. In Table 5 the results of the Bartlett and KMO tests is displayed. 
Table 5:-Validity Test Result

\begin{tabular}{|c|c|c|}
\hline \multicolumn{2}{|c|}{ KMO and Bartlett's Test } & 0,726 \\
\hline Kaiser-Meyer-Olkin Measure of Sampling Adequacy & 1121,329 \\
\hline Bartlett's Test of Sphericity & Approx. Chi-Square & 435 \\
\hline & Df & 0,000 \\
\hline
\end{tabular}

Based on Table 5, the value of KMO was found to be 0.726 - a value above the recommended value of 0.5 . Likewise, the value of Bartlett's Test of Sphericity showed a significant value of 0,000 . This means that there was a high correlation between the AIS Characteristic indicators so the AIS Characteristic indicators could be further tested into factor analysis using the PCA method.

\section{Principal Component Analysis (PCA):-}

Before running the PCA, it is necessary to see the value of Anti-image Matrice (MSA) in advance whether there is a value of less than 0.05; if there is an MSA value of less than 0.05; then the indicator must be removed and retested. In the AIS indicator data, the MSA value of less than 0.05 was found for AIS9; therefore, AIS9 was not included in the following Matrice Anti-image test. In the second testing phase, the MSA value for all indicators was greater than 0.05. The next step was to review the value of communalities. The lower the value of communalities, the weaker the relationship between the indicator and the factors formed. Based on the total variance table explained, it can be seen that the indicators were grouped into seven factors with eigenvalue of greater than 1 . The eigenvalue indicated the contribution of each factor if there were 10 factors extracted. If 10 factors were extracted into 7 factors, the total variance was $70.13 \%$. This means that $70.13 \%$ of the AIS Characteristic variable can be explained by the 7 factors formed.

Table 6:-PCA Result

\begin{tabular}{|r|r|r|r|}
\hline & \multicolumn{3}{|c|}{ Initial Eigenvalue } \\
\hline Components & Total & \% of Variance & 35,60 \\
\hline 1 & 10,32 & 35,60 & 45,13 \\
\hline 2 & 2,77 & 9,53 & 51,34 \\
\hline 3 & 1,80 & 6,21 & 57,04 \\
\hline 4 & 1,65 & 5,70 & 61,64 \\
\hline 5 & 1,34 & 4,60 & 66,05 \\
\hline 6 & 1,28 & 4,41 & 70,13 \\
\hline 7 & 1,18 & 4,08 & \\
\hline
\end{tabular}

After reviewing the eigenvalue values of each indicator and group formed, the next step was to look at the loading factors of each factor formed. In Table 7, it appears that the factors formed and the indicators were based on the results of PCA analysis. It can be seen that Factor 7 only had one indicator (single indicator). Therefore, justification of Factors 6 and 7 was needed by looking qualitatively at the indicator items in the questionnaire to be able to group indicators of AIS21, AIS23, and AIS30 into groups that had similar statements in nature.

Table 7:-Factors Considered in Selecting Accounting App (Stage 1)

\begin{tabular}{|l|l|}
\hline Factor & \multicolumn{1}{|c|}{ Indicator } \\
\hline 1 & AIS4, AIS11, AIS12, AIS14, AIS17, AIS18, AIS24, AIS25. \\
\hline 2 & AIS5, AIS10, AIS3, AIS15, AIS16, AIS26. \\
\hline 3 & AIS3, AIS6, AIS19, AIS29. \\
\hline 4 & AIS1, AIS2, AIS7, AIS8. \\
\hline 5 & AIS20, AIS22, AIS27, AIS28. \\
\hline 6 & AIS23, AIS30 \\
\hline 7 & AIS21. \\
\hline
\end{tabular}


After regrouping based on the value of loading factors, the indicators, and the relevance of the indicator statement, the researchers found there were five groups or five factors with the following grouping (as seen on Table 8).

Table 8:-Factors Considered in Selecting Accounting App (Stage 2/Final)

\begin{tabular}{|c|l|}
\hline Factor & \multicolumn{1}{|c|}{ Indicator } \\
\hline 1 & $\begin{array}{l}\text { AIS4, AIS11, AIS12, AIS14, AIS17, AIS18, } \\
\text { AIS24, AIS25. }\end{array}$ \\
\hline 2 & AIS5, AIS10, AIS13, AIS15, AIS16, AIS26. \\
\hline 3 & $\begin{array}{l}\text { AIS 3, AIS6, AIS19, } \\
\text { AIS29. }\end{array}$ \\
\hline 4 & $\begin{array}{l}\text { AIS1, AIS2, AIS7, } \\
\text { AIS8. }\end{array}$ \\
\hline 5 & $\begin{array}{l}\text { AIS20, AIS21, AIS22, AIS23, AIS27, AIS28, } \\
\text { AIS30. }\end{array}$ \\
\hline
\end{tabular}

The process of naming each factor will be discussed further in the discussion section.

\section{Discussion:-}

In this section, the interpretation of the results of data analysis earlier described will be discussed further. This study aims to explore the factors considered by SME owners in selecting accounting app. Grouping indicators that have been collected through previous studies is carried out using factor principal component analysis.

The grouping of indicators used in this questionnaire aims to collect indicators that have robust links to one particular factor, so that they can form certain constructs. From the results of factor analysis, AIS9 which contains features modification was not considered by respondents in choosing or using accounting app. This might be due to the features that exist in the accounting app as both package and customization app have used features that are very flexible, so it is easy to modify according to the needs of the company.

The results of rotated factor components show that there are seven factors formed as presented in Table 7. The results of grouping in Table 7 contain one factor with a single indicator (factor 7). Since basically the construct is measured by several indicators and based on the consideration of the difficulty of factors with a single indicator, Factor 7 is subjectively allocated to the factors with the most related indicators. Similarly, Factor 6 which contains two indicators is allocated to the most related factor. In accordance with these considerations, five factors are formed as shown in Table 8.

The factors formed are then given the names according to the indicators designed, but also with the consideration of naming in the previous studies (Abu-Musa, 2005; Muhrtala \& Ogundeji, 2014). Factor 1 consists of AIS4, AIS11, AIS12, AIS14, AIS17, AIS18, AIS24, and AIS25. The indicators included in Factor 1 contain statements about the prominence of operational factors such as the use of databases in daily transactions, sales calculation facilities and taxes, the ability of app to be integrated with MS Excel and the presence of helping features. Therefore, Factor 1 is named an operational factor.

Factor 2 consists of AIS5, AIS10, AIS13, AIS15, AIS16, and AIS26. This factor consists of indicators related to features or completeness that should be present in the accounting app. These indicators include, among other things, complete transaction features; sales, financial report generation, as well as inventory and purchase modules, and financial statement ratios. Factor 2 is named a completeness factor. Factor 3 consists of AIS3, AIS6, AIS19, AIS29. Factor 3 is related to indicators of ease of customization, such as the ability of accounting app that can be customized to the size of the company, the agility of accounting app with current company needs, and the existence of warning system about the unexpected company condition. Factor 3 is named a personalization factor.

Factor 4 consists of AIS1, AIS2, AIS7, AIS8. This factor is related to features that support accounting app, among others, the suitability of accounting app with company infrastructure and the ability of accounting app in supporting the company's operational activities, in the present and also for the future. Factor 4 is named a supporting factor.

Factor 5 consists of AIS20, AIS21, AIS22, AIS23, AIS27, AIS28, and AIS30. The indicators in Factor 5 are related with the ability of accounting app to integrate with other app including the use of devices like gadgets or 
smartphones, the display modification of the financial statement, the ability of accounting app to modify transaction documents, and the modification of the input screen. This is support the mobility of SME owners, so accounting app should be more strategic in that they fulfill flexibility for the needs, mobility and innovation of the company. Thus, Factor 5 is given the name a strategic factor.

The factors considered in choosing accounting app for SMEs in Indonesia consist of operational, completeness, personalization, support, and strategic factors. Operational factors are the capabilities of the accounting app to support current business operations. For instance, if a company sells goods or services, the current accounting app should have a feature that is able to make bills that can be used for both. Similarly, if a company currently sells its products through e-commerce, the current accounting app must also be integrated with e-commerce so that the company can easily find out how many sales it has brought about (Abu-Musa, 2005; Muhrtala \& Ogundeji, 2014). The completeness factor is related to the completeness of the features possessed by the accounting app. The modules available in accounting app are taken into consideration by SME owners in Indonesia in choosing accounting app. The completeness of the current features and modules in supporting current and future business operations becomes an important consideration for respondent; as is also found in the study of Abu-Musa (2005).

Personalization factors are related to modifications to the output of accounting app that are tailored to the needs of the company. A good accounting app should be personalized according to the user needs. The ability of the accounting app to be modified consists of several levels, starting from the level of forms, financial reports, databases, and displays (Abu-Musa, 2005). The next factor is the support factor. This factor relates to the facilities and infrastructure of the company. It is a condition where the current accounting app has been integrated with several devices that have been owned by the company, such as spreadsheet (MS Excel), or other app that have a marketing function (e-commerce) (Muhrtala \& Ogundeji, 2014). Support factors can also be related to networks and relationships with government, customers, and suppliers (Liu \& Chen, 2018). The last factor is strategic, namely the ability of accounting app to meet the company's strategy in the future, including the ability of accounting app to integrate with other devices, such as devices that are currently widely used by SME owners. The use of devices is very widespread because of its flexibility in meeting all needs and in accordance with the current lifestyle, namely high mobility (Muhrtala \& Ogundeji, 2014).

\section{Conclusions and Limitation:-}

This study aims to explore factors are considered by SME owners in Indonesia in choosing accounting app. The results shows that the factors considered by SME owners in Indonesia in selecting accounting app are operational, completeness, personalization, support, and strategic. Operational factors are related to the support of accounting app for the sustainability of the company's operational activities. Completeness factors are related to the features available in the accounting app - it should be complete so that it can support current and future business operations. Personalization factors are related to the flexibility of accounting app in modifying the output generate as user need. Support factors are related to facilities and infrastructure that must be owned by the company before using the accounting app so that the app can run smoothly. The last factor is strategic. It is the ability of accounting app in meeting the needs of the company in the future, including the ability of accounting app to be integrated with other devices.

This study is an exploratory research, so further research must be conducted to find the construct of the selection of accounting app for SME. This research is also limited with regard to data collection because it only uses primary data in the form of questionnaires at one time. A longer (longitudinal) and in-depth study is consequently required. There needs to be further research with various methods of collecting and processing data to get a more comprehensive construct of accounting app selection. The number of MSME practitioners in the East Java region is very large, but not all of them can be surveyed; therefore, future research is expected to expand the respondents, so that generalization making can be more convincing.

\section{References:-}

1. Abu-Musa, A. 2005. The Determinates of Selecting Accounting App: A Proposed Model. The Review of Business Information Systems, vol. 9, no. 3, pp. 85-110.

2. Al-dmour, A., Al-Fawaz, KM., Al-dmour, R., and Allozi, NM. 2017. Accounting Information Systems and its Role on Business Performance: A Theoritical Study. Journal of Management and Strategy, vol. 8, no. 4, pp. 7987. 
3. Amanamah, RB., Morrison, A., Asiedu, K. 2016. Computerized Accounting Systems Usage by Small and Medium Scale Enterprises in Kumasi Metropolis, Ghana. Research Journal of Finance and Accounting, vol. 7, no. 16 , pp. 16-29.

4. El Louadi, M. 1998. The Relationship among Organization Structure, Information Technology and Information Processing in Small Canadian Firms. Canadian Journal of Administrative Sciences, vol. 15, no. 2, pp. 180-199.

5. Fisher, DM., and Fisher, SA. 2001. For Rent: Are you considering an ASP for your accounting functions? The National Public Accountant, vol. 46, issue 6, August, pp. 16-18.

6. Fitriati, A., and Mulyani, S. 2015. Factors that Effect Accounting Information Success and its Implication on Accounting Information Quality. Asian Journal of Information Technology, vol. 14, no. 5, pp. 154-161.

7. Hall, J. 2011. Construct, Deliver, Maintain Systems Project", Dewey, R. (Ed.), Accounting Information Systems, Centage Learning, Mason, OH, pp. 633-636.

8. Ismail, N.A., King, M. 2005. Firm Performance and AIS Alignment in Malaysian SMEs. International Journal of Accounting Information Systems, vol. 6, no. 4, pp. 241-259.

9. __., and Zin, RM. 2009. Usage of Accounting Information among Malaysian Bumiputra Small and Medium Non-manufacturing Firms. Journal of Enterprise Resource Planning Studies, vol. 2009, pp. 1-7.

10. Jadhav, AS., Sonar, RM. 2011. Framework for Evaluation and Selection of the App Packages: A Hybrid Knowledge Based System Approach. The Journal of System and App, vol. 84, pp. 1394-1407.

11. Khazanchi, D. 2005. Information Technology (IT) Appropriateness: The Contingency Theory of "Fit" and IT Implementation in Small and Medium Enterprises. The Journal of Computer Information Systems, vol. 45, no. 3, pp. 88-95.

12. Lutfi, AA, Idris KM, and Mohamad R. 2016. The Influence of Technological, Organizational, and Environmental Factors on Accounting Information Systems Usage among Jordanian Small and Medium-sized Enterprises. International Journal of Economics and Financial, vol. 6, special issue (S7), pp. 240-248.

13. Markus, M., and Tanis, C. 1997. Learning from Adopters' Experiences with ERP: Problems Encountered and Success Achieved. Journal of Information Technology, Vol. 15, pp. 245-265.

14. Moghaddam, A., Baygi, S., Rahmani, R., and Vahediyan, M. 2012. The Impact of Information Technology on Accounting Scope in Iran. Middle-East Journal of Scientific Research, vol. 12, no. 10, pp. 1344-1348.

15. Muhrtala, O., and Ogudenji, MG. 2014. Determinates of Accounting App Choice: An Empirical Approach. Universal Journal of Accounting and Finance, vol. 2, no.1, pp. 24-31.

16. Sarosa, S. 2008. The Adoption of Tailor-Made IT-Based Accounting Systems Within Indonesian SMES from Actor Network Theory Perspective. Proceeding The 2nd Accounting Conference, 1st Doctoral Colloquium, and Accounting Workshop, Depok, 4-5 November 2008.

17. Simamora, B. Analisis Multivariat untuk Pemasaran. Jakarta: Gramedia Pustaka Utama, 2005.

18. Simkin, MG. 1992. Decision support tools for choosing accounting app. The CPA Journal, online, diakses tanggal 12 Februari 2018.

19. Smirat, BY. 2013. The Use of Accounting Information by Small and Medium Enterprises in South District of Jordan (an Emprical Study). Research Journal of Finance and Accounting, vol. 4, no. 6, pp. 169-175.

20. Spathis, C., and Constantinides, S. 2004. Enterprise Resource Planning Systems' Impact on Accounting Processes. Business Process Management Journal, Vol. 10 No. 2, pp. 234-247.

21. Tijani, OM., and Mohammed, AK. 2013. Computer-based Accounting Systems in Small Medium Enterprises: an Empirical Evidence from a Randomized Trial in Nigeria. Universal Journal of Management, vol. 1, no. 1, pp. 13-21.

22. Van de Ven, A. H., and Drazin, R. 1984. The Concept of Fit in Contingency Theory. Minnesota.

23. Venkatesh, V., Thong JYL., Xu, X. 2012. Consumer Acceptance and Use of Information Technology: Extending the Unified Theory of Acceptance and Use of Technology. MIS Quarterly, vol.36, no.1, pp157-178.

24. Widyaningdyah, A. 2014. Adopsi Sistem Informasi Akuntansi pada Usaha Kecil dan Menengah: Sudahkah Selaras? Studi Empiris pada Usaha Kecil dan Menengah di Surabaya dan sekitarnya. Jurnal Keuangan dan Perbankan, vol. 11, no. 1, pp. 11-26. 